\title{
Comments on Kelly
}

\author{
Robert L. Kahn \\ University of Michigan
}

I like Jim Kelly's paper very much. His insistence on the interdependence between practice and research is well stated, and it is a message that we need to hear, especially in a period when the social branches of psychology have become increasingly individual, cognitive, and uninvolved in social settings. So I found much to agree with in Jim Kelly's paper, not because I think his is the only way to define the relationship between research and practice but because it is $a$ way, an important way, and one that is in danger of getting lost.

Kelly's advice, however, is not easy to take, because it advocates one point of view in a controversy rather than proposing an integrative solution of the opposing arguments. As he says, his "thesis is that if the community psychologist can develop a research style where the research activity is specifically and genuinely participative, several positive outcomes will follow" (p. 583).

This means that the topics to be investigated will be determined consensually by the community psychologist and the subjects in the research, and that the subjects will be both informed and influential as the research proceeds. Easily said, and noble in its ring, but markedly divergent from the methods of science as developed in the physical sciences and borrowed, more or less, by the social sciences, perhaps especially our own.

Those methods are primarily experimental, in their logic as well as their design, and they involve, among other things:

- introducing one variable at a time as the experimental manipulation

- conducting research in the laboratory

- putting the control of the treatment (timing, etc.) in the hands of the experimenter

- determining the experimental treatment by the scientific purpose of the inquiry, largely irrespective of the wishes or immediate well-being of the subjects 
- once the experiment is under way, maintaining the previously set schedule of treatment without change

- limiting the information of subjects regarding the experimental design and purpose (indeed, often misinforming them)

- establishing a control group of subjects who will not receive the experimental treatment or even be aware of the experiment.

One has only to begin listing these methodological attributes to be reminded of the difficulties and costs involved in attempting to apply them to human populations. Community psychology is not unique among the branches of our discipline in encountering these problems, but it faces them more directly and more unavoidably than most. The variables of interest to community psychologists are generated in community settings, and the possibility of reproducing them in strength in the laboratory is limited. Community psychologists, almost by virtue of their chosen subdiscipline, have also chosen to work in natural settings. Moreover, community psychology is a new field, still in the process of early discovery or invention of its major concepts. That fact also locates the community psychologist in the community, searching out the forces at work in that setting that shape the patterns of human behavior and the quality of human lives.

I therefore concur with Kelly's view that community psychologists have a special contribution to make to the relationship between theory and practice, because they face most stringently certain issues that the social sciences all share: how to develop and validate scientific findings without the usual experimental power (and disregard of subject well-being) that scientific method had demanded and scientific ethics justified.

I will go still further with my points of agreement. The four topics that Kelly cites as exemplars of the potential areas in which community psychology and the methods of embeddedness and participation might contribute are well chosen and persuasive: family and community origins of leadership; social settings that promote the development of persons and of other social settings; social occasions and celebrations that promote a sense of community; and understanding the formation of social networks. If these are a random sample of research issues that Kelly's advocated methods generate, I am encouraged. The same can be said for the notion of the "light touch" as an interactive style that promotes these kinds of positive outcomes.

What does that leave to disagree with, or at least to worry about? I will mention a few such points, in the order in which they are mentioned in Jim's paper.

First, I do not understand how the proposed embeddedness of community psychologists in community settings validates constructs. Such "embeddedness" may generate insights and assist in the development of 
hypotheses, but what does it mean to say that the validity of "constructs are [sic] generated from the community?" (p. 582) I think that, irrespective of the source of conceptual ideas, the familiar criteria of validity-prediction, convergence, etc. - persist. Folk wisdom on such issues is often invaluable but often incorrect, and we must bring our own scientific criteria to the problem of validation.

Second, I worry about the "consensual definition of the [research] task" (p. 583). By this phrase Kelly means not mere informed consent but major participation by the research subjects in determining the issues to be investigated. But the jigsaw puzzle of reality is vast and complex. What happens when the logic of inquiry or the recent pattern of discovery sets priorities for the investigator that are low on the priority list of his or her community subjects (participants)? For example, I share Jim Kelly's interest (and perhaps those of his community subjects) in the phenomenon of social support, but I am more interested in discovering the connections between formal structural properties of networks and their support functions that I am in following the lead of the light touch or other community-generated hunches. What am I to do, subordinate my research priorities or disobey Kelly's participative injunction (at least in this respect)?

Third, although I like very much the notion of research that is directly helpful to subjects and I feel the authenticity of Chris Argyris's early research experience in the bank, I do not believe that the motive of help-seeking necessarily goes hand-in-hand with truth telling (p. 583). People who want help will be motivated to tell the truth to potential help-givers if they think that doing so increases the prospects for getting help. Doctors and therapists learn quickly that patients who most want help and expect it are not necessarily rendered truthful thereby.

Fourth, I find the implicit values and explicit goals of contributing "to the empowerment of individuals and the preservation of social settings" ( $p$. 584) to be, if not Panglossian, at least too optimistic for my experience and temperament. There are individuals (and groups) whose empowerment I do not want to increase and settings that I do not wish to help preserve. I suspect Jim Kelly and I might agree on them. What, then, am I to make of the goal as stated?

As I consider the areas of agreement and disagreement between Jim and me with respect to the choosing of research issues, the use of methods (or their exclusion), and the feasibility of finding and researching "topics that illuminate both basic and practical" questions, I see in my mind's eye a fourfold table in which the columns are labeled "basic" (yes and no. respectively) and the rows are labeled "practical" (yes and no, respectively). The upper left-hand cell thus meets the criteria of both basic research or theory and of practicality (as seen by participants). Jim Kelly and I have no disagreement about such topics; they are high on the research agenda. 
The lower right cell, of course, identifies topics that have neither scientific nor practical value to give them high place on our research agenda, and neither Jim nor I wants to see them researched.

But what about the diagonal cells, in which practicality seems to urge a priority that science cannot agree to, or vice versa? And what is the relative size of those four cells? To what extent is the game zero-sum?

And finally (and perhaps more constructively), what can we do to define our mission and methods in ways that will minimize the size of those controversial diagonal cells? Jim Kelly's paper begins to answer that question and does so in ways that will encourage others to continue the process. For both these things, we are in his debt.

\section{REFERENCE}

Kelly, J. G. (1986). Context and process: An ecological view of the interdependence of practice and research. American Journal of Community Psychology, 14, 581-589. 